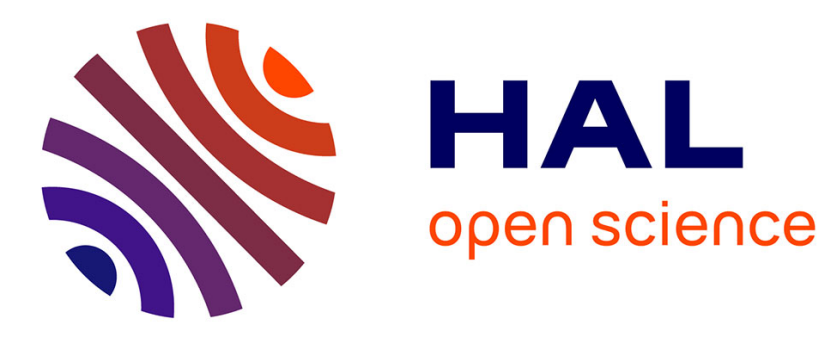

\title{
Model Based Approach for Online Monitoring of Aluminum Production Process
}

Lucas José da Silva Moreira, Gildas Besancon, Francesco Ferrante, Mirko Fiacchini, Herve Roustan

\section{- To cite this version:}

Lucas José da Silva Moreira, Gildas Besancon, Francesco Ferrante, Mirko Fiacchini, Herve Roustan. Model Based Approach for Online Monitoring of Aluminum Production Process. TMS 2021 Annual Meeting \& Exhibition, Mar 2020, San Antonio, United States. pp.566-571, 10.1007/978-3-030-364083_78. hal-02444509

\author{
HAL Id: hal-02444509 \\ https://hal.science/hal-02444509
}

Submitted on 3 Dec 2020

HAL is a multi-disciplinary open access archive for the deposit and dissemination of scientific research documents, whether they are published or not. The documents may come from teaching and research institutions in France or abroad, or from public or private research centers.
L'archive ouverte pluridisciplinaire HAL, est destinée au dépôt et à la diffusion de documents scientifiques de niveau recherche, publiés ou non, émanant des établissements d'enseignement et de recherche français ou étrangers, des laboratoires publics ou privés. 


\title{
Model Based Approach for Online Monitoring of Aluminum Production Process
}

\author{
Lucas José da Silva Moreira, Gildas Besançon, Francesco Ferrante, Mirko \\ Fiacchini, Hervé Roustan
}

\begin{abstract}
In Hall-Heroult process for aluminium production, estimating the alumina concentration and the anode-cathode distance $(A C D)$ remains a challenge. One of the difficulties arises from the fact that it is not possible to measure those quantities continuously during the pot operation. This article presents a novel approach for on line estimating alumina concentration and $A C D$ in a regular aluminum-reduction pot cell using a Linear Kalman Filter. This is done by using an appropriate dynamical model for the pot, which is obtained by combining the first principle modeling and experimental identification of alumina concentration behavior from irregularly sampled data. Moreover, a dynamical model for the pot resistance is identified as a function of the alumina concentration and $A C D$ data. The proposed approach is validated on an industrial platform.
\end{abstract}

Key words: Aluminum electrolysis, state estimation, Kalman filter.

\section{Introduction}

Aluminum manufacturing is a challenging industrial area based on the Hall-Heroult process $[1,2]$. In this setting, model and control challenges arise from the limitations in the process information continuously available, which can lead to inaccurate

L. J. da Silva Moreira ( $₫)$, G. Besançon, F. Ferrante and M. Fiacchini

Univ. Grenoble Alpes, CNRS, Grenoble INP, GIPSA-lab

Grenoble, France

e-mail: lucas-jose.da-silva-moreira, gildas.besancon, francesco.ferrante, mirko.fiacchini @grenoble-inp.fr

H. Roustan

Rio Tinto, Laboratoire de Recherche des Fabrications

Saint Jean de Maurienne, France

e-mail: herve.roustan@ riotinto.com 
results [3]. Moreover, this restrains the process production efficiency since it is risky to work with uncertainties or imprecise data [4].

During the electrolysis reaction which is the basis of the process, the anodecathode distance $(A C D)$ is continuously affected by liquid aluminum production, carbon consumption. Other aspects affect the $A C D$ as the electric perturbations and changes in the composition of the bath. An inappropriate $A C D$ can impact in the efficiency of the process and safety conditions. In fact, a large $A C D$ decreases the pot cell production and a small value can cause a short-circuit between the produced aluminum and the anode [5]. Unfortunately, it is not possible to measure it during the process operation, and its dynamical behaviors is very difficult to represent in full details. See $[3,6]$ for more details.

Another essential variable in aluminum production is the dissolved alumina concentration $\left(w \mathrm{Al}_{2} \mathrm{O}_{3}\right)$. Generally, it is required to keep it in a specific range to avoid the formation of sludge or the onset of anode effect [7]. Although monitoring importance, measurements this quantity continuously is costly. In common operation, just a few samples per week are manually taken, which makes it difficult to obtain an experimental model.

In practice, to monitor and regulate aluminum production, an indirect measurement is used: the pseudo-resistance. This signal is computed using the line current and pot voltage direct measurements. Other important variables for the Hall-Heroult process like aluminum fluoride concentration, bath temperature, metal height, etc. are only sporadically measured. The pseudo-resistance is used to determine the alumina feed rate injected in the system. The alumina feeding rate is based on the alternation of slower (underfeeding) and faster (overfeeding) periods than the rate corresponding to normal consumption of the cell [8]. The feeding periods alternation occurs when the rate of variation of pseudo-resistance exceeds a set value. Moreover, it is usually defined a setpoint resistance and thermal balance to ensure control stability and obtain a good current efficiency. This value is adjusted by the $A C D$ regulation [8]. Many authors indicate that the pseudo-resistance could not be a good indicator for the operation $[9,10]$.

Because of this lack of continuous measurements, nonlinear estimators have been developed by a few researchers [11, 3, 12]. All of them are focused on a two-step procedure: Obtain a nonlinear model and apply an estimator strategy. However, an imprecise model can generate inaccurate results. As the Hall-Heroult process has a complex dynamics, it is not easy to find a proper model that reproduces its behavior. Moreover, it is necessary to have an initial $A C D$ measurement which is not possible during operation. To overcome these limitations, some authors have been working on iterative filtering procedures yet, these require more computation effort [4].

In this paper, an online monitoring technique based on Linear Kalman filtering state-estimation is proposed. It uses a model that combines physical-chemical preliminary knowledge and experimental identified aspects. This system representation enables a real-time overall alumina concentration and $A C D$ monitoring which can be used to avoid anode effects and improve the production. This procedure is validated with operational collected data and tested for different conditions in APXe50 pot 
cell localized in Laboratoire de Recherches de Fabrications (LRF) in Saint Jean de Maurienne, France.

The paper is organized as follows: The modeling approach and validation are presented in Section 2. The online monitoring and experimental results are explained in Section 3. The conclusions are discussed in Section 4.

\section{Modeling}

The process description of this paper is based on dynamical equations using the manipulated and process variables available in modern aluminum reduction cells. Initially, the $A C D$ modeling is explained based on a chemical balance. Moreover, some simplified models for the alumina concentration and the pot resistance are developed. At the end of this section, an overall state-space model for the aluminum process is given. It is assumed that the pot is always in regular operation. In particular, it is assumed that line current and alumina pot feeding do not undergo on a significant overshoot.

\subsection{Anode-Cathode Distance}

The $A C D$ is defined as the difference between the heights of aluminum produced $\left(A l_{\text {Height }}\right)$ and carbon consumed $\left(C_{\text {Height }}\right)$. Its dynamics depends on the anodes busbar beam movement $(B M)$ and the initial distance $\left(A C D_{i n i}\right)$ as follows:

$$
A C D(t)=A l_{\text {Height }}(t)-C_{\text {Height }}(t)+B M(t)+A C D_{\text {ini }}
$$

The beam movement derivative is considered as one of the system inputs $\left(u_{1}\right)$ :

$$
u_{1}(t)=\frac{d}{d t} B M(t)
$$

Using the electrochemical relations of chemical balance it is possible to compute the $A C D$ and its variation in discrete-time for computer implementation by the following equation structure:

$$
A C D[n+1]=A C D[n]+T_{S}\left(u_{1}[n]+\beta I[n]\right)
$$

where $T_{s}$ is the sampling time, $\beta$ is a combination of pot physical-chemical parameters and $I$ is the line current applied to the system. As it is not possible to measure the $A C D$ during the operation, the value of $\beta$ is computed using theoretical values for a regular pot operation. Moreover, during the metal tapping, it is not considered that the beam is moving. 


\subsection{Alumina Concentration}

The variation of the alumina concentration $\left(\frac{d}{d t} w \mathrm{Al}_{2} \mathrm{O}_{3}\right)$ is given by the difference between the concentration amount of dissolved alumina $\left(w \mathrm{Al}_{2} \mathrm{O}_{3 i n}\right)$ that is resulted from the alumina injected in the pot by the feeders and the amount of alumina that is consumed by the chemical equation ( $\mathrm{wAl}_{2} \mathrm{O}_{3 \mathrm{cons}}$ ). Hence the following chemical balance can be considered:

$$
\frac{d}{d t} w A l_{2} O_{3}(t)=w A l_{2} O_{3 i n}(t)-w A l_{2} O_{3 c o n s}(t)
$$

It can be assumed a quick alumina solving [13]. This approach does not consider any agglomeration of the alumina powder since the dissolution constant is $0.099 s^{-1}$ and the sampling rate is 1 minute.

The frequency of the feeders $(F)$ is considered as one of the system inputs $\left(u_{2}\right)$ :

$$
u_{2}[n]=F[n-D]
$$

where $D$ is a constant time-delay due to alumina diffusion lag.

Therefore, equation (4) can be rewritten in discrete-time as:

$$
w l_{2} O_{3}[n+1]=w A l_{2} O_{3}[n]+T_{s}\left(\alpha_{1} u_{2}[n]-\alpha_{2} I[n]\right)
$$

where $\alpha_{1}$ and $\alpha_{2}$ are a combination of pot physical-chemical parameters.

As in LRF pots the aluminum concentration is measured a few times a day and in the same pot position, it is possible to identify an experimental model from the collected data and obtain values of $\alpha_{1}$ and $\alpha_{2}$ for regular operation.

Initially, the time delay $D$ is estimated using unconstrained nonlinear optimization techniques and validated for different data set. Equation (6) needs a previous value of $w \mathrm{Al}_{2} \mathrm{O}_{3}$ to calculate the next concentration. Then, the model is initialized with a measurement and the simulation is started using the signals of $u_{2}$ and $I$. Every time that there is a new alumina concentration data collection, the model is reinitialized to improve the simulation results.

In Fig. 1, it is shown a comparison between the model simulation using parameters $\alpha_{1}$ and $\alpha_{2}$ estimated with the collected alumina concentration and the respective inputs. It is possible to verify that the model provides a very good prediction of the plant behavior. The mean absolute relative error between the model and the measurements is $3.5176 \%$. Hence, this model can be considered validated and used to simulate and predict alumina concentration over long time horizons.

\subsection{Pot Resistance}

The pot resistance is an indirect measurement calculated via the pot voltage and line current. The pot voltage is modeled by a complex relation that uses $A C D$ and alumina 


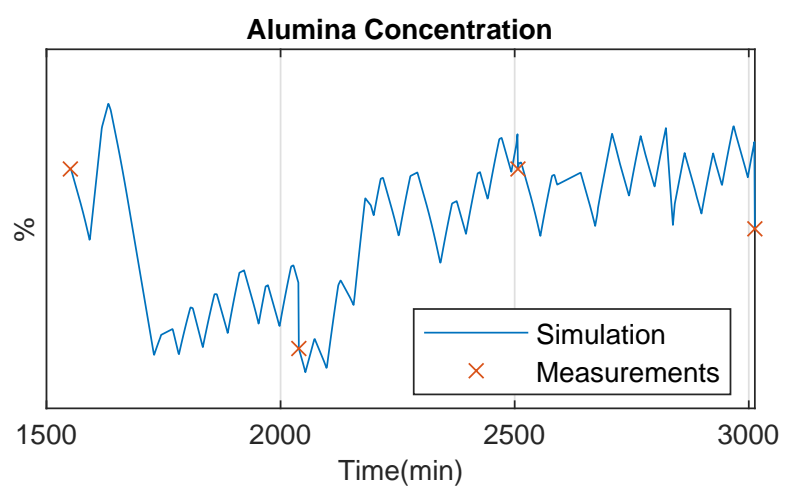

Fig. 1 Alumina Concentration Model Validation

concentration [14]. Besides that, it is taken into account other system operational parameters that cannot be measured continuously or that are not measured. Therefore, this makes it difficult to obtain a precise model. Aiming to obtain a simpler resistance model, it is assumed that all these unknown factors are constant during the pot operation . Moreover, it is not necessary to know any information about them, only the $\mathrm{ACD}$ and $\mathrm{wAl}_{2} \mathrm{O}_{3}$ values are required.

It is known that the resistance model generates curves as shown in Fig. 2 for different $\mathrm{ACD}$ and $\mathrm{wAl}_{2} \mathrm{O}_{3}$. During the regular operational specification, the low and high alumina concentrations plot regions i.e. the anode effect and sludge formation areas are avoided. Then, the curves shown in Fig. 2 can be parameterized by the following equation:

$$
R(t)=c \times w A l_{2} O_{3}^{2}(t)+(d+e \times A C D(t)) w A l_{2} O_{3}(t)+(f+g \times A C D(t))
$$

where $c, d, e, f$ and $g$ are constant parameters to be determined.

Equation (7) can be derived to compute the resistance variation in discrete-time by the following relation:

$$
\begin{aligned}
R[n+1]= & R[n]+\left(e \times \Delta w A_{2} O_{3}[n] A C D[n]\right. \\
& +\left(2 c \times \Delta w A l_{2} O_{3}[n]+e \times \Delta A C D[n]\right) w A l_{2} O_{3}[n]+d \times \Delta w A l_{2} O_{3}[n]+g \\
& \times \Delta A C D[n])
\end{aligned}
$$

where:

$$
\begin{gathered}
\Delta A C D[n]=\frac{A C D[n]-A C D[n-1]}{T_{s}} \\
\Delta w A l_{2} O_{3}[n]=\frac{w A l_{2} O_{3}[n]-w A l_{2} O_{3}[n-1]}{T_{s}}
\end{gathered}
$$

Notice that equation (8) needs an initial $A C D$ value and this values is not measurable. Only the $A C D$ variation is calculated by equation (3). This problem can 


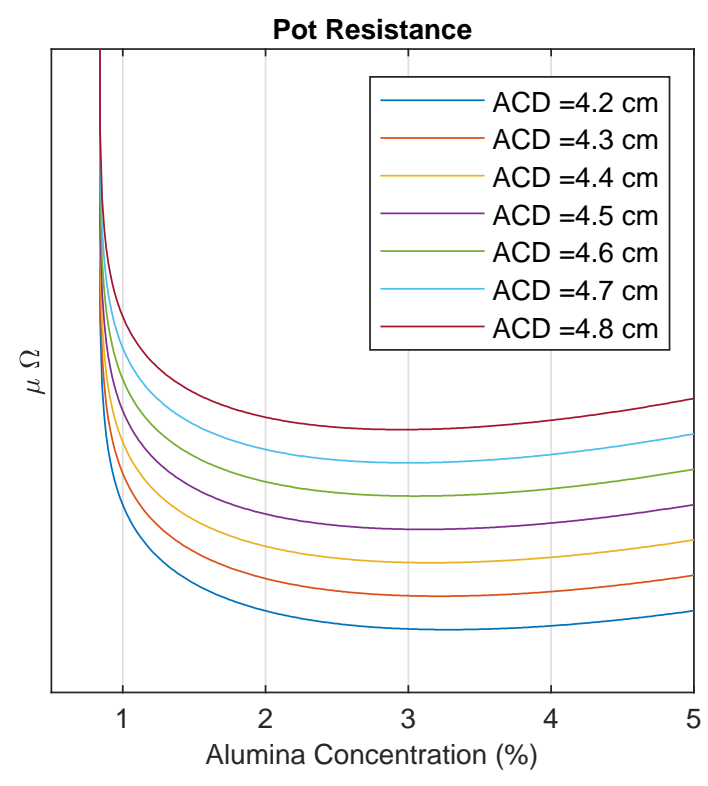

Fig. 2 Typical pot resistance curve as function of alumina concentration and $A C D$

be solved by re-arranging equation (8) to set as the identifiable parameter the initial $A C D$ combined by the other unknown variables.

In Fig. 3, a comparison between the model output simulation and real measurements is shown. The mean absolute error index computed for this data set is $2.2054 \%$. However, it can be seen a small drift in Fig. 3. This happens because the model structure from equation (8) reproduces the resistance variation and needs an initial value.

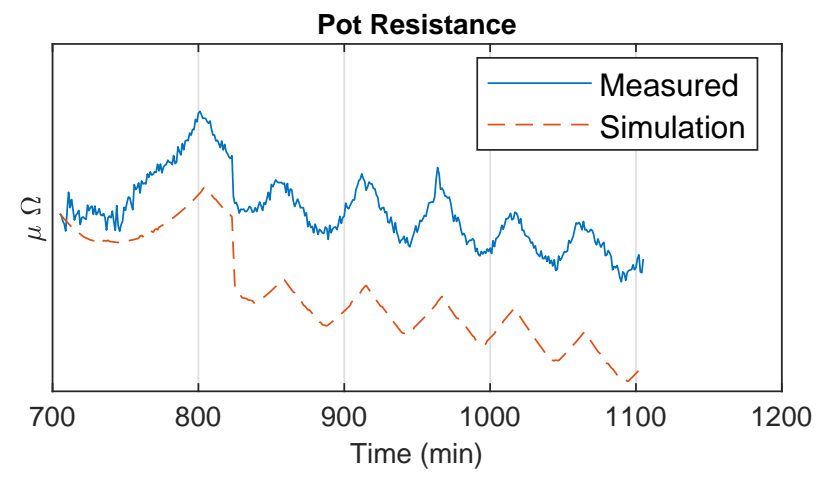

Fig. 3 Resistance Model Validation 


\subsection{State-Space Model}

From the results described in previous sections, it is possible to obtain a discrete-time state-space model of the plant, with state vector defined by:

$$
\mathbf{x}[n]=\left[\begin{array}{l}
x_{1}[n] \\
x_{2}[n] \\
x_{3}[n]
\end{array}\right]=\left[\begin{array}{c}
R[n] \\
A C D[n] \\
w A l_{2} O_{3}[n]
\end{array}\right]
$$

The current intensity is not considered as a control input because, due to the operational constraints, it cannot be manipulated. Hence, this signal is considered as a measured disturbance in the system.

Organizing equations (3), (6) and (8) results in the following description:

$$
\left\{\begin{array}{l}
\mathbf{x}[n+1]=\left[\begin{array}{ccc}
1 & a_{12}[n] & a_{13}[n] \\
0 & 1 & 0 \\
0 & 0 & 1
\end{array}\right] \mathbf{x}[n]+\left[\begin{array}{l}
b_{1}[n] \\
b_{2}[n] \\
b_{3}[n]
\end{array}\right] \\
R[n]=\left[\begin{array}{lll}
1 & 0 & 0
\end{array}\right] \mathbf{x}[n]
\end{array}\right.
$$

where:

$$
\begin{aligned}
a_{12}[n] & =e\left(\alpha_{1} u_{2}[n]-\alpha_{2} I[n]\right) \\
a_{13}[n] & =\left(2 c\left(\alpha_{1} u_{2}[n]-\alpha_{2} I[n]\right)+e\left(u_{1}[n]+\beta I[n]\right)\right. \\
b_{1}[n] & =\left(d\left(\alpha_{1} u_{2}[n]-\alpha_{2} I[n]\right)+g\left(u_{1}[n]+\beta I[n]\right)\right) \\
b_{2}[n] & =\left(u_{1}[n]+\beta I[n]\right) \\
b_{3}[n] & =\left(\alpha_{1} u_{2}[n]-\alpha_{2} I[n]\right)
\end{aligned}
$$

which all the parameters known.

This model representation permits to design a Linear Kalman filter usage [15], even with a nonlinear model. This is justified because equation (12) is affine in the state. Hence, it is possible to recover the state vector for a given input set. This makes it possible to use the valid model for online $A C D$ and $w \mathrm{Al}_{2} \mathrm{O}_{3}$ monitoring.

\section{Online Monitoring}

As the model is valid and it is possible also to organize it in a state-space form, the states can be estimated using a linear observer fed with the plant inputs and outputs. The schematic implementation is shown in Fig. 4. The estimation of the state signals for pot resistance $(\hat{R})$, alumina concentration $\left(w A \hat{l}_{2} O_{3}\right)$, and anode-cathode distance $(A \hat{C} D)$ are calculated in real-time from inputs and output signals. Therefore, this makes it possible an online state monitoring. 


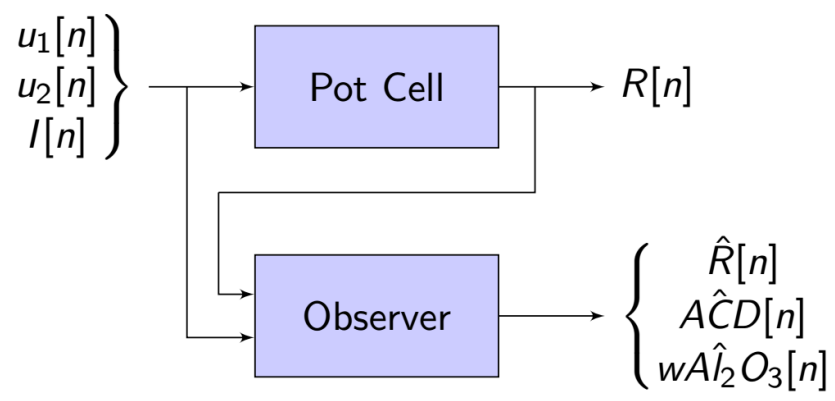

Fig. 4 Schematic Observer Implementation

The observer selected is a Kalman Filter. It requires first to tune the noise matrices to perform the estimations. As the chosen sampling time is 1 minute, the noise covariance level is set in small value for the process and measurement matrices. The covariance matrix has to be tuned as well. According to the chosen matrix values, the convergence can be faster or slower. In this case, it is recommended a higher value for the $A C D$ covariance than other states since it is not possible to measure it. Further details in Kalman Filter can be found in [16].

To ensure the performance, the filter was tested using different initial values of $A C D$ and $\mathrm{wAl}_{2} \mathrm{O}_{3}$. The resulting estimations for each of them, labeled as $1,2,3$ and 4 , are compared with real measurements of $R$ and values computed by the model for all states, as shown in Fig. 5. Notice the fast convergence for all state estimations, less than 1 hour, even with different initial conditions. As $R$ is measured, it converges faster than other states variables. The other signals estimations take more time to converge to a value closer to those computed by the model. Therefore, the efficiency of the state estimations can be guaranteed and they can be used for online monitoring of a regular pot cell.

This online monitoring can be used to predict local anode effects as well, around the alumina collection area. This is done by monitoring a small concentration of alumina. In Fig. 6, it is shown the alumina concentration model simulation between to measurements and the surrounding anodes currents measurements labeled with the respective position number. It is possible to verify that after alumina concentration reaches small values, the currents start in anode 21 to have a disturbance behavior. After some time, it is verified in the individual current anodes measurements many peaks. This characterizes an anode effect in the pot cell that was noticed by model based monitoring model based system.

\section{Conclusion}

In this article, a novel approach for online monitoring of aluminum reduction cells based on the model is proposed. This approach combines the available signals in 

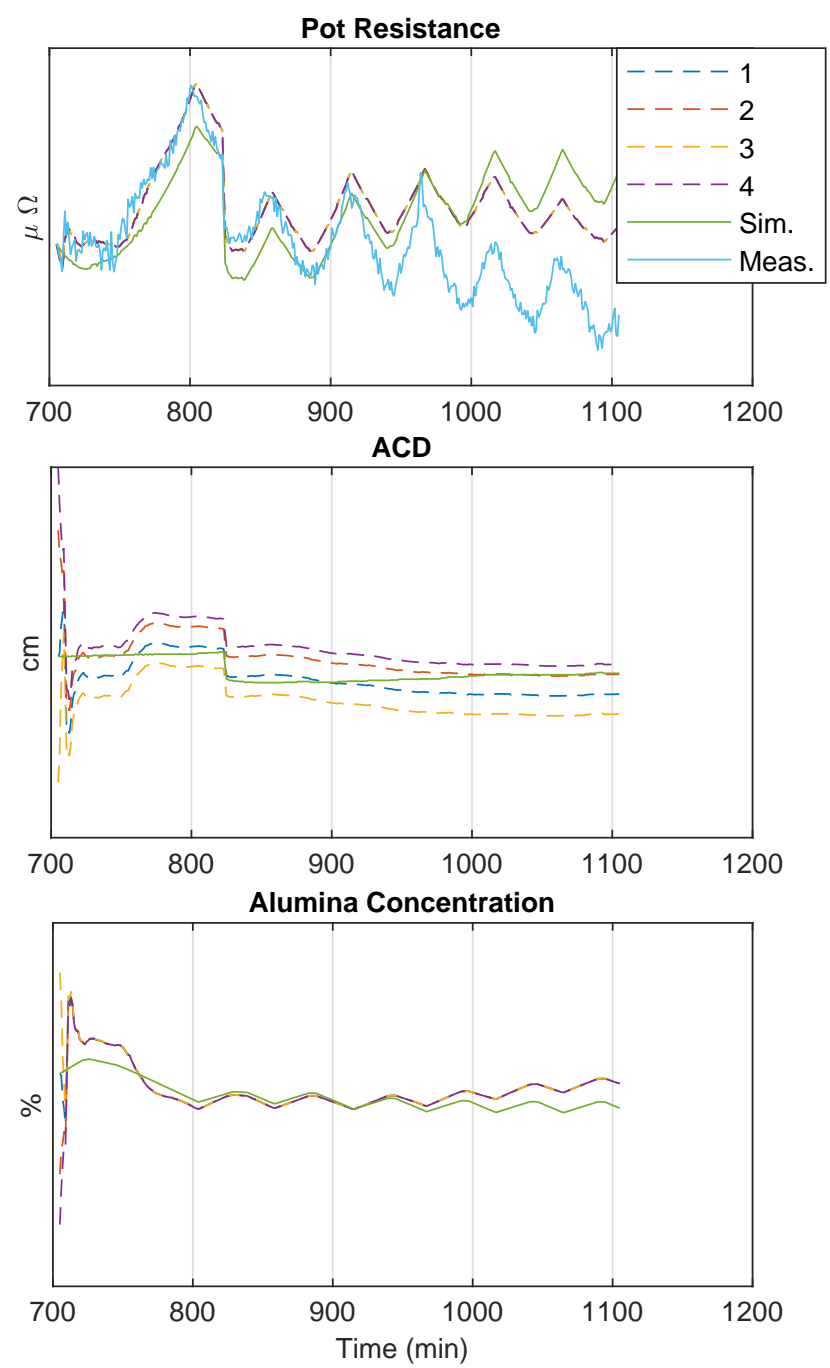

Fig. 5 States Estimations

the pot cell, physical-chemical knowledge, and system identification methods to obtain a state-space model. This representation captures only the regular operation dynamics. Then, it is possible to obtain a simple model that captures the desired operational dynamics, neglecting complex relations. This model structure can be applied to a Linear Kalman Filter and used it to estimate two important signals for the pot operation: $A C D$ and $w \mathrm{Al}_{2} \mathrm{O}_{3}$.

The estimation results were tested using experimental data, which showed good accuracy for $A C D$, and alumina concentration estimation, as well as resistance 

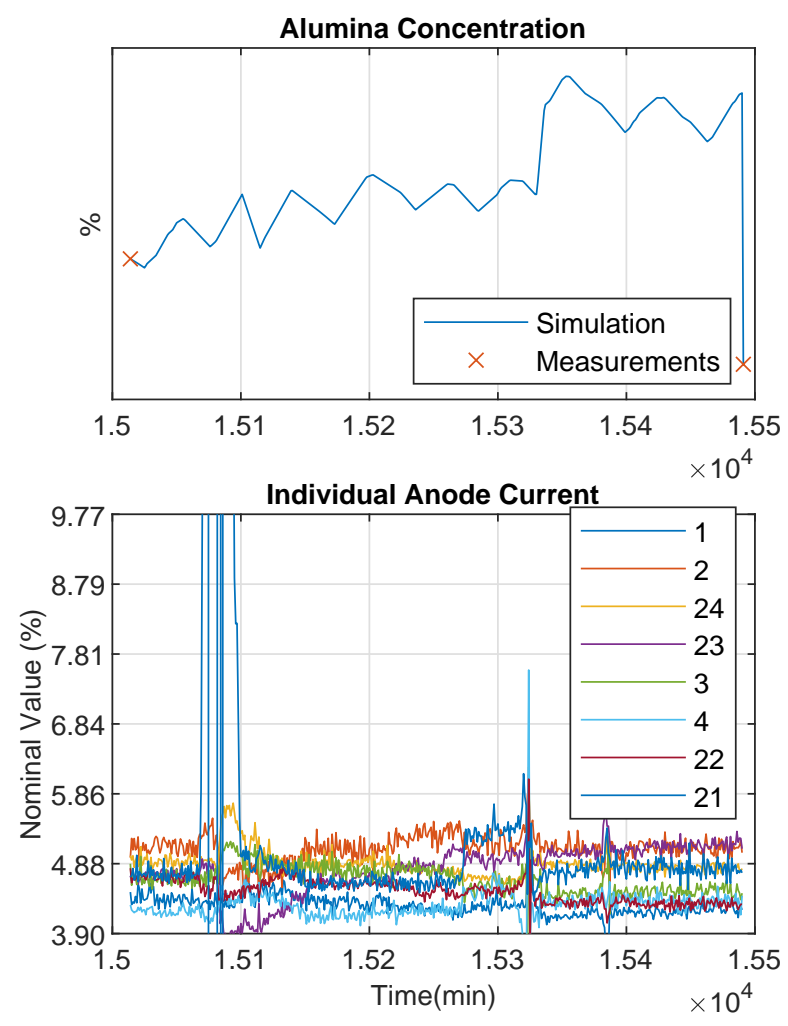

Fig. 6 Anode Effect Monitoring

prediction. Moreover, it can allow to detect local anode effects based on the alumina concentration monitoring. In conclusion, the proposed method seems to provide promisingly efficient results without knowing much about the pot dynamics. Then, it can be used for pot monitoring during regular operation.

\section{Acknowledgments}

The authors wish to acknowledge project PIANO funded by the French Fonds Unique Interministériel (FUI).

\section{References}

1. K. Grjotheim, Aluminium Electrolysis: Fundamentals of the Hall-Héroult Process. Aluminium-Verlag, 1982. 
2. K. Grjotheim and B. J. Welch, Aluminium Smelter Technology: A Pure and Applied Approach. Aluminium-Verlag; 2nd edition, 1980.

3. S. R. Jakobsen, K. Hestetun, M. Hovd, and I. Solberg, "Estimating alumina concentration distribution in aluminium electrolysis cells," IFAC Proceedings Volumes, vol. 34, no. 18, pp. 303-308, 2001.

4. Y. Yao and J. Bao, "State and parameter estimation in Hall-Héroult cells using iterated extended Kalman filter," IFAC-PapersOnLine, vol. 51, no. 21, pp. 36-41, 2018.

5. J. T. Keniry, G. C. Barber, M. P. Taylor, and B. J. Welch, "Digital processing of anode current signals: an opportunity for improved cell diagnosis and control," Light Metals, pp. 1225-1232, 2001.

6. Y. Yao, C.-Y. Cheung, J. Bao, M. Skyllas-Kazacos, B. J. Welch, and S. Akhmetov, "Estimation of spatial alumina concentration in an aluminum reduction cell using a multilevel state observer," AIChE Journal, vol. 63, no. 7, pp. 2806-2818, 2017.

7. G. P. Bearne, "The development of aluminum reduction cell process control," JOM, vol. 51, no. 5, pp. 16-22, 1999.

8. P. Homsi, J.-M. Peyneau, and M. Reverdy, "Overview of process control in reduction cells and potlines," in Essential Readings in Light Metals, pp. 739-746, Springer, 2016.

9. Y. Yao, C.-Y. Cheung, J. Bao, and M. Skyllas-Kazacos, "Monitoring local alumina dissolution in aluminum reduction cells using state estimation," in Light Metals 2015, pp. 577-581, Springer, 2015.

10. W. Haupin and E. J. Seger, "Aiming for zero anode effects," in Essential Readings in Light Metals, pp. 767-773, Springer, 2016.

11. S. Kolås, B. Foss, and T. S. Schei, "State estimation is the real challenge in NMPC," in International workshop on assessment and future directions of nonlinear model predictive control, Pavia, Italy, 2008.

12. K. Hestetun and M. Hovd, "Detecting abnormal feed rate in aluminium electrolysis using extended kalman filter," IFAC Proceedings Volumes, vol. 38, no. 1, pp. 85-90, 2005.

13. P. Biedler, Modeling of an aluminum reduction cell for the development of a state estimator. $\mathrm{PhD}$ thesis, West Virginia University, 2003.

14. W. Haupin, "Interpreting the components of cell voltage," in Essential Readings in Light Metals, pp. 153-159, Springer, 2016.

15. R. E. Kalman, "A new approach to linear filtering and prediction problems," Journal of basic Engineering, vol. 82, no. 1, pp. 35-45, 1960.

16. D. Simon, Optimal state estimation: Kalman, $H$ infinity, and nonlinear approaches. John Wiley \& Sons, 2006. 